\title{
Risk Perception of Plastic Pollution: Importance of Stakeholder Involvement and Citizen Science
}

\author{
Kristian Syberg, Steffen Foss Hansen, Thomas Budde Christensen, \\ and Farhan R. Khan
}

\begin{abstract}
Risk perception has a significant impact on how society reacts to a given risk. There have been cases where a mismatch between the actual risk and the perception of it has led to poor decisions on societal initiatives, such as inappropriate regulatory measures. It is therefore important that the perception of risk is based on an informed foundation acknowledging the biases and drivers that inevitably go with risk perception. Plastic pollution differs in regard to other classical risks, such as those posed by chemicals or genetically modified organisms (GMOs), since the pollution is more visible and already has a significant magnitude. At the same time, everyone is familiar with using plastic, and our daily lives are highly dependent on the use of plastic. This offers some potential to strengthen the societal risk perception and subsequently implement effective measures to address the pollution.
\end{abstract}

In this chapter, we define eight risk perception drivers (voluntariness, control, knowledge, timing, severity, benefit, novelty, and tangibility) and relate these drivers to plastic pollution. We discuss the process in which plastic pollution has been recognized as an important environmental problem by scientists, the public, and policy makers and elaborate on how the eight risk drivers have influenced this process. Plastic pollution has several of the characteristics that can enhance people's perception of the risk as being important and which has generated great awareness of the problem. The chapter finally discusses how risk perception can

\author{
K. Syberg $(\bowtie)$ and F.R. Khan \\ Department of Science and Environment, Roskilde University, Roskilde, Denmark \\ e-mail: ksyberg@ruc.dk

\section{S.F. Hansen} \\ Department of Environmental Engineering, Technical University of Denmark, Lyngby, \\ Denmark \\ T.B. Christensen \\ Department of Human and Technology, Roskilde University, Roskilde, Denmark
}


be improved by greater stakeholder involvement and utilization of citizen science and thereby improve the foundation for timely and efficient societal measures.

Keywords Citizen science, Plastic pollution, Public participation, Risk perception, Stakeholder involvement

\section{Introduction}

Risk is often portrayed as a function of hazard and exposure or in other words as being determined by the probability of an adverse event and the magnitude of this event's consequences [1]. The scientific capabilities for quantifying both probabilities and magnitude related to many risks are often relatively uncertain, which implies that quantification of risk is inherently uncertain [2]. This means that interpretations of risk are very important for human's response to the risk, since the risk perception, rather than an (often unknown) actual estimation of risk, will guide societal response to the risk. Uncertainty furthermore plays a profound role in regard to human's psychological responses to risks [1]. This implies that psychology is important in regard to how we as society react to a given risk, but elements such as communication and social structures also influence risk behavior as they frame the overall social and technical perception of both hazard and exposure.

Risk perception can be explained as the subjective assessment of a negative incident happening together with our concern of the consequences. The term risk perception is perhaps mostly associated with Ulrich Beck's description of the "risk society" in his book of the same name [3]. Beck argues that society must (and will) respond to the growing threat from ecological degradation by acting in a reflexive way [3]. This reflexivity can manifest in different manners, and Beck describes how a public demand for regulation can push a political debate, by drawing upon historical cases regarding oil drilling platforms and nuclear power plants [3]. Since the risk perception is thus often a strong driver for regulation, it has received increasing attention from stakeholders and legislators. In Sweden and Norway, parliamentarians now devote about three times as much attention to risk issues as they did in the first half of the 1960s, as reflected in their submitted private bills [1].

In this chapter we first describe how the historical development of risk perception can be explained within a theoretical framework. After the introduction of these theoretical boundaries, the chapter focuses on risk perception of plastic pollution in a historical perspective, followed by an analysis of stakeholder's role in development of public risk perception and policy measures. The last part of the chapter addresses how citizen science [4] can be an important method to improve societal risk perception of plastic pollution and finally discusses how the concept of citizen science can be expanded to allow for greater stakeholder involvement and better communication between scientist and citizens. Such communication can be vital in regard to informing about plastic pollution and thus improve the foundation for development of risk perception among stakeholders - including citizens and policy makers. For a discussion on the socio-ecological risks of microplastics from a global perspective, see [5]. 


\section{The Theory of Risk Perception}

Even though Beck's book on "risk society" might be the best known description of the importance of risk perception, the scientific theory predates Beck's book. One earlier example is that of Slovic et al. [6], who conducted a study where they evaluated several drivers for societal risk perception. One of their conclusions was that the greater a risk is perceived to be, the greater is the public demand for action [6]. The aim of the study was to explain why some hazards were perceived as extreme and others caused less concern, despite inconsistencies in the respective expert opinions [6]. This work built upon earlier studies, where Starr [7] found that risk seemed to be easily accepted if it was associated with benefits and had a voluntary nature. Risk of death in a traffic accident is a classic example of such acceptable risk.

In this paper we will distinguish eight drivers for risk perception (Table 1). The first driver that frames risk perception is voluntariness (driver 1). A person is more likely to accept a given risk if the risk exposure takes place on a voluntary basis compared to an imposed risk. Risks that are perceived to be uncontrollable generally cause greater concern (driver 2: control). The risk associated with flying as a passenger in an airplane, for example, often causes more concern than highway driving in passenger cars. A third driver (driver 3: knowledge) is the degree of familiarity associated with the risk. A known and quantifiable risk (such as the risk of getting cancer from smoking) is often more easily acceptable than the risk posed from an unknown entity. The timing (driver 4) of the risk is also important to its perception. Persons exposed to a given risk are more likely to accept the risk if it is imposed gradually over time than if the risk is imposed instantaneously. Risks with

Table 1 Eight main drivers for risk perception

\begin{tabular}{l|l|l}
\hline & $\begin{array}{l}\text { Drivers for risk } \\
\text { perception }\end{array}$ & Explanation \\
\hline 1 & Voluntariness & $\begin{array}{l}\text { If the exposure to the risk factor is voluntary, it is more likely to be } \\
\text { accepted compared to a superimposed risk }\end{array}$ \\
\hline 2 & Control & $\begin{array}{l}\text { If the risk is perceived to be uncontrollable, it is viewed as more severe } \\
\text { A known risk is perceived more acceptable than an unknown and } \\
\text { unfamiliar risk }\end{array}$ \\
\hline 4 & Knowledge & $\begin{array}{l}\text { If a hazard has instant and disastrous potential, it is perceived as a } \\
\text { higher risk, than hazards, which pose gradual risk over time }\end{array}$ \\
\hline 5 & Severity & $\begin{array}{l}\text { Greater perceived risk is correlated with how big a part of the popu- } \\
\text { lation that is perceived as being at risk }\end{array}$ \\
\hline 6 & Benefits & $\begin{array}{l}\text { Risks that are associated with perceived benefits are often deemed } \\
\text { more acceptable than risk without any obvious advantage }\end{array}$ \\
\hline 7 & Novelty & $\begin{array}{l}\text { Risks from novel entities are generally perceived as more risky than } \\
\text { existing risks }\end{array}$ \\
\hline 8 & Tangibility & $\begin{array}{l}\text { A risk that is more tangible is perceived as more severe than a risk that } \\
\text { is abstract and elusive }\end{array}$ \\
\hline
\end{tabular}

Table constructed after $[6,8]$ 
greater potential for immediate disastrous outcome to the individual such as a nuclear power plant meltdown are often perceived as worse than those that inflict slow and gradual damage. A fifth driver is the severity of the risk (driver 5: severity), measured in terms of how many people it might affect, as there seems to be a correlation between number of people potentially affected and the perceived risk. The sixth driver (driver 6: benefit) for risk perception is the degree of benefits that are associated with the risk. People are more likely to accept risks if they believe that taking the risks is associated with high degree of benefit. Driving in cities with intense traffic is an example, where the risk of ending up in a car accident is perceived acceptable due to the benefit of transportation in a car. The seventh driver is the novelty of the risk (driver 7: novelty). Risks associated with new technologies and novel entities are generally perceived as more dangerous than older and more familiar risks, even if the statistical risks are comparable or even lower for the novel risk. The eighth and final driver relates to how tangible the risk is (driver 8: tangibility). It is important to distinguish between risks that by the individual are perceived as tangible and risks that are perceived as abstract and elusive. Abstract and elusive risks, such as those posed by climate change, are typically far more difficult to mobilize political action against, and therefore political action will only take place when the risk has become visible and acute, and by then, it will often be too late to take political action [8]. Giddens himself refers to this phenomenon as the "Giddens paradox" [8].

Before addressing risk perception of plastic pollution in respect to these drivers, it is feasible to explore two historical cases of other yet somewhat related types of risk - i.e., those of hazardous chemicals and genetically modified organisms (GMOs).

\subsection{Risk Perception of Hazardous Chemicals and GMOs}

In 2009 the European Commission published a study on Europeans' risk perception of potential hazardous chemicals in household products [9]. The results are interesting in the light of the abovementioned framework for "risk" perception, biases, and drivers. The group of chemicals that were associated with the highest perceived risk were pesticides and herbicides used for home use. Of the respondents that answered, $70 \%$ said that this group of chemicals posed a risk in their perception. At the other end of the scale were toothpaste $(7 \%)$ and hair shampoo $(11 \%)$.

The report concludes that people generally view personal risks lower than risks to the general public. This could be due to a perception of the personal risk being easier to control [9]. The report concludes that if a product is known to be risky, citizens could translate this knowledge into taking precautionary measures, which would again lower the perceived risk. This is in line with the theories about risk perception, i.e., the level of voluntariness as well as the level of control of the risk. Another important aspect for risk perception of household chemicals is the potency of the chemicals [9]. Chemical with high hazardous potential was generally 
perceived as more risky than less potent chemicals. This could be part of the reason why pesticides and herbicides were perceived as most risky, since these chemicals are designed to kill. The level of control might also be an important driver for the perceived risk in the study (driver 2 in Table 1). Pesticides and herbicides are spread in the environment leading to a loss of control, whereas exposure to toothpaste and hair shampoo is conducted under controlled circumstances (not taking the exposure to the environment from wastewater into consideration). Furthermore, there is a general trust that cosmetic products such as sunscreen are tested and that any potential risk is therefore known to science [9], again in correlation with risk perception driver 3 (whether a risk is understood and quantifiable or unknown and unfamiliar). The report finally concludes that there is a correlation between the educational levels of citizens and their awareness of potential risk but also that the better a risk is understood, the less concerned citizens are about it. These observations are also in accordance with the risk perception, biases, and drivers presented in Table 1.

The use of genetically modified organisms (GMOs) is another controversial topic which has spun an intense debate about risk perception since their introduction in the 1970s [10]. Especially, European citizens have been very reluctant to accept the risk associated with GMOs, not at least due to the high degree of scientific uncertainty associated with the use. Since the 1990s, the debate about the use of GMOs is mainly centered on crops and food products, whereas GMOs in pharmaceuticals have gained broader acceptance [10]. This tendency can possibly be explained by a number of the biases and drivers in Table 1 . For instance, citizens will generally view a risk as more tolerable if there is an obvious benefit from taking the risk (driver 6) or if the risk is not directly affecting the individual subject, for example, if the use of a GMO at a farm is affecting the ecosystem on a general level and to a less extent the individual farmer. Production of new pharmaceuticals is often viewed positively, whereas enhanced crop yield might be less related to a consumer benefit and often more related to maximizing the economic outcome to the benefit of the farmer and only very indirectly the consumer.

Another aspect that has had importance for public risk perception of GMOs is the so-called yuck factor [11]. It is a term that was first used to describe citizens' reluctance toward new technologies with unknown consequences: a classic example being the unwillingness toward using purified wastewater as drinking water, regardless of how effective the cleaning is [11]. The "yuck factor" can thus be seen as an emotional response to something that people might find repulsive or in other ways conflicting with their beliefs and values. The emotional attitude toward novel technologies is framed by many factors on the individual level (e.g., age, gender, education, profession, previous experience with technologies, etc.) and on the societal level (e.g., structure and level of educational, media and legal system, norms and values, etc.). The "yuck factor" is therefore only a simplistic explanation to some of the public aversion toward GMOs [11]. The perception that food should be grown in the field and not in the laboratory surely also plays a role for some citizens' reluctance toward accepting this technology. GMOs thereby challenge a public idea of the relation between nature and food as a public set of values, 
regardless of what might be expressed as objective and scientific truth by the expert community. The "yuck factor" is important in two types of scenarios where a modification to what is perceived as a "natural system" changes this system drastically, whether it is altering the genes in a plant or spreading of artificial objects such as plastic in the environment. First, if the modification is linked with a limited scientific understanding and communication about possible negative consequences, or second if the scientific understanding is conflicting with core values in society and therefore not accepted as trustworthy.

\section{Risk Perception of Plastic Pollution and the Role of Stakeholders}

After this initial introduction to the field of risk perception, the remaining part of the chapter will focus on how plastic pollution is perceived today and how future efforts with better integration of stakeholders might facilitate a better and more informed risk perception among citizens. However, prior to that we address the historical risk perception of plastic pollution.

\subsection{Historical Development}

Scientific focus on plastic pollution has increased markedly over the last decades, especially since the turn on the millennium. The first notion of seabirds ingesting plastic debris was published in the 1960s [12]. At this point, research into environmental contamination with plastic debris was a small field, and few papers were published through the 1960s and 1970s (see [13-15]). However, Carpenter and Smith [16] were the first to notice that plastic accumulated in specific oceanic zone, in their Science publication of plastic debris in the Sargasso Sea. It was also in the 1970s that the first reports of beach litter were published [17]. More frequent reports on occurrence were consistently being published from the 1980s (e.g., [18, 19]), and it was in this decade that a systematically growing trend of marine pollution with plastic was first reported [20]. These findings initiated political discussions about the problem and were followed with political initiatives such as the MARPOL Annex V aiming at reducing plastic wastes at sea [21]. However, the Annex was considered optional, and ratification was required by UN member states before it enter into force in 1988 [21] (for a broader discussion on the regulation of microplastics, see [22]). Also in 1988 a report from the US National Oceanic and Atmospheric Administration (NOAA) described the concentration of plastic debris in the North Pacific Gyre. This was later followed by the work of Moore et al. [23], who compared abundance of plastic pellets and planktonic organism in the North Pacific Gyre. They concluded that while planktons were five times as abundant as 
plastic pellets when measured by number, the mass of the plastic pellets exceeded planktonic mass six times [23]. This "litter artifact" in the middle of the ocean was popularly called the "Great Pacific Garbage Patch," which had a significant impact on the public perception of the problem. The linguistic framing of the plastic pollution repelled the public by playing on the yuck factor, similar to the case of GMOs described above. The pollution was also unknown to many, making the novelty of the problem significant (driver 7). On the other hand, this description did give some backlash since it created an illusion of islands of plastics floating around in the ocean. Since such islands do not exist in reality, some commentators have argued that the environmental problem was exaggerated and that this could erode citizens' trust in institutions [24]. Plastic pollution was not perceived as such a big risk in the decades after the first reports were published. This can be explained using several of the risk perception drivers (Table 1). Since plastic pollution was first reported as a phenomenon on the open ocean and not related directly to severe impacts on marine species and ecosystems, it was not perceived as a risk with "potential for disaster" (driver 4) nor a contamination that impacted a large group of people (driver 5). Debris in the middle of the ocean has no direct link to any human populations per se, which might also have affected the lack of public response (driver 5). Furthermore, oceanic pollution is abstract and not so tangible since it is not easily visible to most people. Therefore, the "Giddens paradox" (driver 8) might also have influenced the lack of perceived risk in these early years. Finally, there was very little information communicated to the public about the problem, for instance, from 2004 to 2010, microplastics were only mentioned a few times in UK newspapers, whereas the number of articles grew markedly in the following years [25]. Since people obviously cannot perceive a risk that they are not aware of, this lack of communication is a final but very important reason for the lack of early alertness to the problem.

\section{Risk Perception of Plastic Pollution and Political Actions Since the 2000s}

Plastic pollution research declined during the 1990s, only to drastically increase after it was verified during the 2000s that plastic was a ubiquitous marine pollutant [17]. Among several important publications, Thompson et al. [26] published a famous paper in science entitled "Lost at sea: Where is all the plastic?" which is being recognized as a major driver for the elevated scientific interest [17]. The significant increase in scientific publications on the topic was followed with increased international media attention and political measures being enforced. Reports about the plastic pollution problem have thus been broadcasted in international media such as Reuters [27], and political measures have been taken in different regions of the world. In 2008 Rwanda banned the use of non-biodegradable plastic bags throughout the country [28]. This ban followed a 
national discussion of plastics' negative environmental impacts, especially due to the extensive physical presence of bags in the environment (also discussed by Khan et al. [29] in this volume). This measure was among the first and most comprehensive political acts to control plastic pollution, and it can to a large extent be explained with the risk perception drivers. The spreading of plastic bags was not an environmental risk that the population faced voluntary (driver 1). Since the plastic bags were further spread throughout the environment, it could be viewed as an uncontrollable risk (driver 2), perhaps even with potential for disasters for the ecosystems affected (driver 4). Since it may appear as there is only very limited societal benefit of the pollution to the end consumer (driver 6), there were strong incentives to address the pollution with political measures. Of course, the use of plastic on a societal level includes a vast amount of technical and economic benefits to both producers and consumers, and the current waste management practices where the majority of waste plastics is either landfilled or incinerated may be perceived by some stakeholders as beneficial to the society.

In Europe the debate about the use of resources, waste handling, and the plastic pollution has been ongoing for several years primarily within the context of waste regulation. The first packaging waste directive (Directive 85/339/EEC) was adopted in the mid-1980s aimed at reducing negative environmental aspects of packaging and packaging waste. The Packaging and Packaging Waste Directive has been amended several times since then (1994, 2003, 2004, 2013, and 2015). The 2015 revision resulted in the adoption of Directive (EU) 2015/720 on reducing the consumption of lightweight plastic carrier bags [30]. The overall framework for waste-related regulation is in the EU described in the Waste Framework Directive (Directive 2008/98/EC) that contains the core principles for waste management in Europe. The Waste Framework Directive is related to several directives that target specific waste streams such as batteries, electronic and electrical equipment, endof-life vehicles, sewage sludge, construction and demolition waste, etc. Many of these waste streams contain plastic, and EU efforts to reduce plastic pollution in the waste sector shall therefore be seen on the background of this wide range of directives. In December 2015, the European Commission launched a Circular Economy (CE) package (also discussed in [31]). The CE package includes proposed revisions to many of the central waste-related directives including the Waste Framework Directive and the Packaging and Packaging Waste Directive. A central element in proposed revisions is common EU-wide 2030 targets for the waste sector. The CE strategy includes five priority areas, one of which is plastic. The commission will in 2017 adopt a strategy on plastic targeting issues such as recyclability, biodegradability, hazardous substances, and marine litter [32].

Microbeads pose a special and interesting case in regard to risk perception of plastic pollution. Microbeads contribute to a relatively small percentage of the total plastic production but have become highly exposed in the media, and risk perception of microplastic is often connected to microbeads. Several campaigns (e.g., Beat the microbead [33]) focus on phasing out microbeads explicitly. Several initiatives have been launched to call for a phaseout of microbeads. In one petition, gathering more than 375,000 signatures called for a ban in the UK [34]. The US state of 
California approved Assembly Bill No. 888 banning the use of plastic microbeads in personal care products by 2020 [35], and a new US initiative aims at banning the use of microbeads in personal care products and cosmetics on a national level by mid-2017 [36]. The Canadian House of Commons have proposed a new order which will add microbeads to the national list of toxic substances, as a response to a vote to take immediate measures to phase out microbeads [37]. The environmental presence of microbeads has been documented [38], and the focus on microbeads is therefore scientifically valid. However, the major problem with plastic pollution seems to stem from other sources [39]. The "yuck factor" has played a role in the risk perception and subsequent political action on microbeads. Plastics in products such as toothpaste are viewed as "unnecessary" (driver 6) and "unnatural." Consumers therefore react emotionally negative toward this new, "unnecessary," and "unnatural" use of microbeads in consumer products, and this consumer attitude can be understood as an example of the "yuck factor." Microbeads thus serve as an example of the importance of risk perception to societal action and furthermore how important risk communication and involvement of citizens can be for societal reactions to an environmental problem.

The second part of the chapter addresses how citizen science has improved the risk perception of plastic pollution and finally discusses how it can be further expanded in order to involve citizens and thereby address the pollution better and further enable citizens to obtain informed perceptions of the plastic pollution problem.

\section{Citizen Science as Concept}

Science as a paid profession started in the later part of the nineteenth century [4]. Up until then scientific data were produced by people who collected the data due to interest. Some famous examples of citizen scientists were Benjamin Franklin and Charles Darwin [4]. Today's citizen science (CS) is most commonly conducted when projects are specifically designed to combine knowledge and expertise from scientists at research institutions with the work of the skilled amateurs, often within conservation biology and monitoring studies [40]. Silvertown [4] proposed that the expanding use of CS is driven by three factors: (1) greater access to the technical tools needed, (2) bringing in additional qualified labor, and (3) a greater demand for outreach within academia. In a historical context, CS has most commonly been used with conservation biology and nature monitoring programs. Examples such as the Atlas Project in Australia, where BirdLife Australia has used CS to obtain more than seven million bird observations for their "Atlas of Australian Bird" [41], and Herbaria@home, where museum collections of wild plants are analyzed by citizens in the UK for more than a decade [42], serve as illustrations of such classic CS projects. CS has however also been used to monitor pollution. The Air Quality Egg Project in the USA and Europe is a CS project that aims at monitoring air quality. It is based on a sensor system designed to allow citizens to collect data on $\mathrm{NO}_{2}$ and 
$\mathrm{CO}$ concentrations outside of their home [43]. The $\mathrm{IDAH}_{2} \mathrm{O}$ Master Water Stewards program, offered by University of Idaho, aims at involving citizens in collection of water quality data in streams in Idaho, USA [44]. In North American citizen scientists have collected data for bird watching programs and have helped scientists develop guidelines for land managers [45]. The increased use of CS can thus be viewed as a way for science to be informed by citizens but at the same time, and very importantly for risk perception, as a means for citizens to obtain a better understanding of the scientific field in focus [46]. As mentioned earlier knowledge is vital for the risk perception. Where risk is perceived as higher by citizens than by experts within the field, it is often the unfamiliarity that is a key psychological driver for risk perception [6]. But there might also be scenarios where citizens are not fully aware of a risk, until they are involved in collecting data for it under a CS program. In these situations, people might underestimate risk due to the lack of knowledge. CS can thus help people to obtain more informed perceptions about a given risk and thereby facilitate a process of transformative learning that can ultimately result in citizens changing the perception of a given problem [47]. Collaboration between citizens and scientists not only influences citizen's risk perception but may also influence the values and beliefs that the scientists possess and ultimately their risk perception as well. This led Gibbons et al. [48] to suggest the distinction between mode 1 and mode 2 researches. Mode 1 research characterizes the traditional disciplinary scientific endeavor in closed scientific communities, and mode 2 research describes a transdisciplinary type of knowledge production where scientists and citizens collaborate to define both problems and solutions. Elements of this way of looking at research can today be found in, for example, the $€ 80$ billion European research and innovation program Horizon2020. Horizon2020 is based on three pillars: the excellence pillar that resembles the mode 1 research, the industrial leadership that mainly focuses on innovation in the private sector, and the Societal Challenges pillar that with requirements for multi-actor approach and co-innovation resembles the mode 2 research.

\section{Citizen Science and Plastic Pollution}

Citizen science has been widely used within the field of plastic pollution [49], often in and around the intertidal zone, e.g., as "beach cleanup" projects. A review conducted by Hidalgo-Ruz and Thiel [49] comparing CS and professional scientist projects concluded that CS can be a useful method for increasing the amount of available information on marine litter. Such events are typically organized by national organizations such as the NOAA in the USA [50] or by private stakeholders such as NGOs. NOAA has developed a mobile application called "Marine Debris Tracker app" (Fig. 1) together with Southeast Atlantic Marine Debris Initiative (SEA-MDI), allowing citizens to report findings of trash from beaches and waterways [51]. The app records the debris location through GPS, and the data can be view directly on the citizens' phone. 

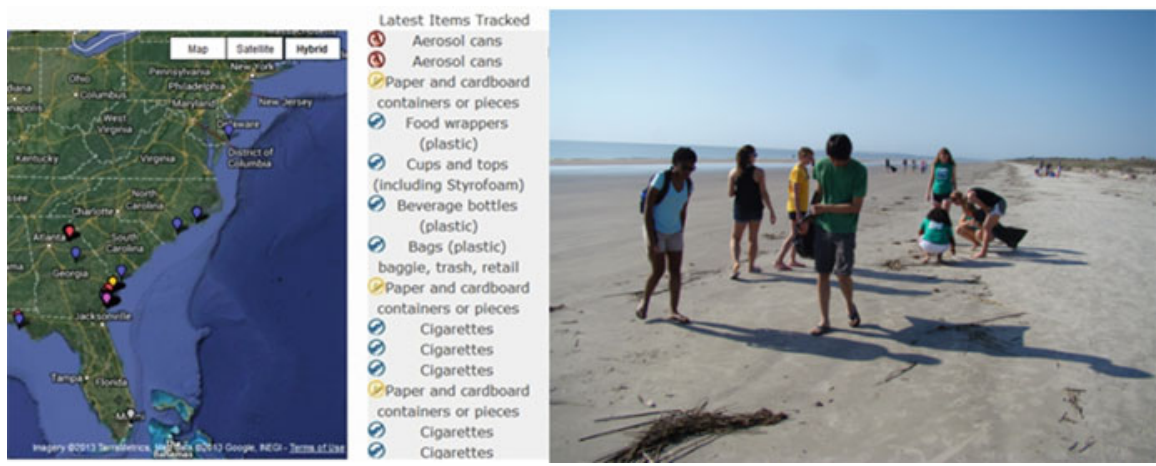

Fig. 1 (Left): Picture showing data marine debris collected and reported with the "Marine Debris Tracker app" made by NOAA Marine Debris Program and the Southeast Atlantic Marine Debris Initiative [50]. (Right): Citizens using the Marine Debris Tracker app (Picture from SEA-MDI)

Similar initiatives have been developed on the other side of the Atlantic in Europe. The European Environmental Agency, an independent agency financed by the European Union, has developed a mobile application called Marine LitterWatch [52] on the same principles as Marine Debris Tracker. Marine LitterWatch is used by scientists and NGOs in at least ten member states [52].

Apart from these stakeholders (scientist and NGOs), students can also play an active role in collecting and monitoring data using these mobile applications (Fig. 2). In the Roskilde Fjord region in Denmark, students collaborated with scientists to generate data on the occurrence of marine litter at 12 beaches around the fjord [53]. The students analyzed the data using a protocol inspired by the Marine LitterWatch protocol [53]. A similar but much larger project has been conducted in Chile [54]. The "National Sampling of Small Plastic Debris" was a CS project, where schoolchildren from 39 (approximately 1,000 students) from continental Chile and the Easter Island participated in the activity [54]. The project documented the distribution and abundance of small plastic debris on Chilean beaches. Scientist validated the data obtained in the program by recounting all samples in the laboratory. The results showed that the students were able to follow the instructions and generate reliable data [54]. Such involvement of students in collecting data serves as an example of the transformative learning discussed by Ruiz-Mallén et al. [47].

Microplastic is not as visible as meso- and macroplastic and therefore not as easily collected in these CS programs. But since the majority of microplastic pollution is secondary microplastic particles - i.e., breakdown products from meso- and macroplastic - the microplastic pollution is closely interlinked with larger plastic debris. Furthermore the majority of marine plastic debris stems from land-based sources [39], making NOAA arguing that beach cleanups are important contribution to marine protection [50], since they provide additional information for monitoring programs and help protect the environment. The development of Marine Debris Tracker app and the EEA Marine LitterWatch illustrates two aspects 

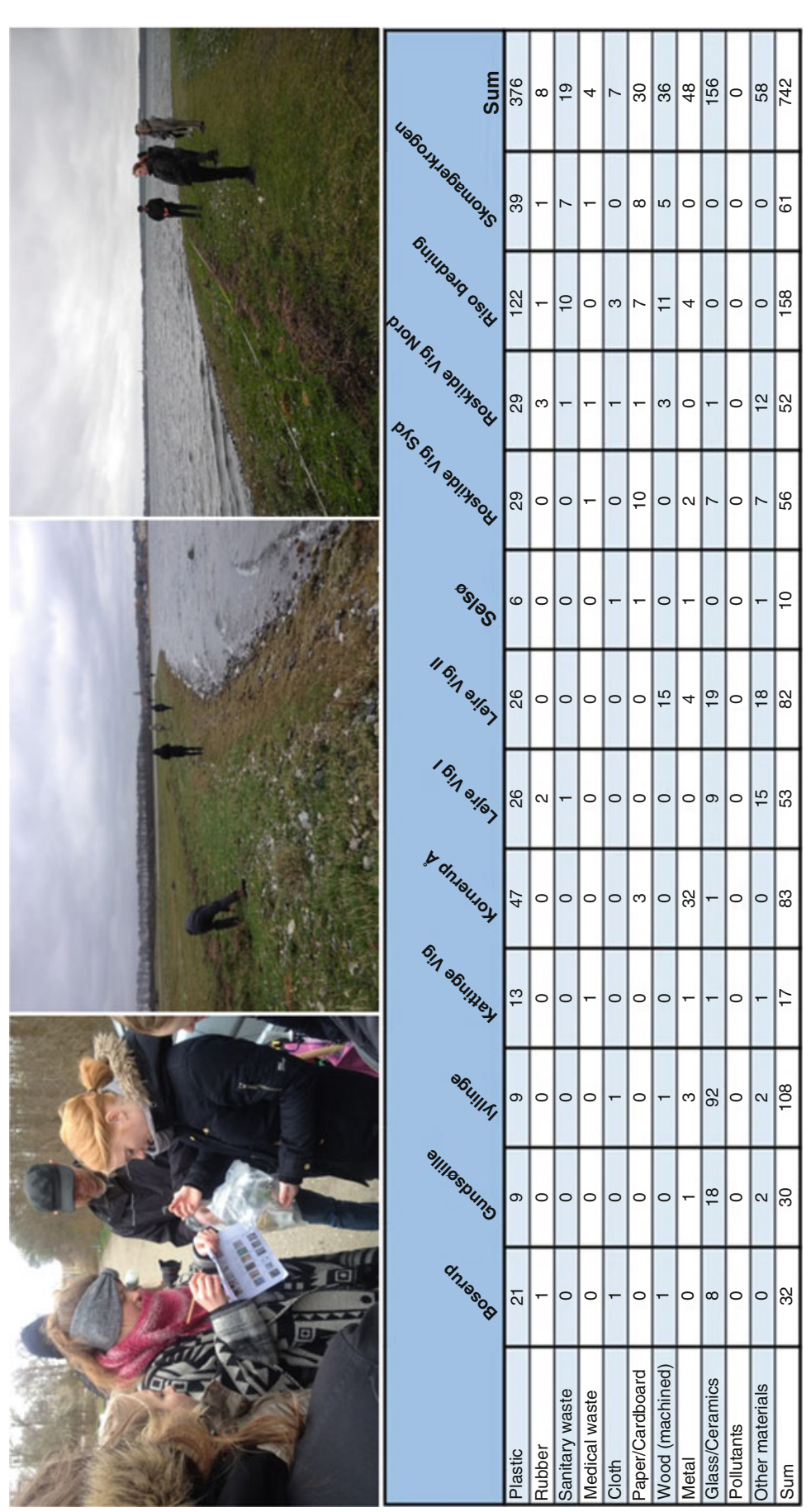

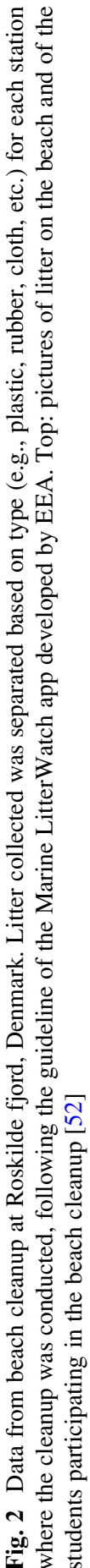


of the CS development within the field of plastic pollution monitoring. Firstly, it serves as an example of how new (mobile) technology enables a systematic gathering of CS-collected data, in accordance with [4] drivers to expansion of CS. Secondly, it illustrates how collaboration between scientist, citizens, and NGOs results in efficient, high-quality data collection and monitoring programs. The quality of data is exactly one of the aspects that have been highlighted as a potential problem with CS-driven data collections [49]. It is therefore important to validate data collected under CS beach cleanup programs, if they are subsequently used in monitoring programs. Lavers et al. [55] found that detection of beach litter varied from 60 to $100 \%$ across various types of plastic. The authors further found variation among different observers, depending on observer experience and biological material present on the beach that could be confused with plastic [55]. The authors found that the color of the plastic debris was an important parameter, with blue fragments having the highest detection probability, while white fragments had the lowest.

In 2005 "International Pellet Watch" (IPW) was launched by Prof. Takada from Tokyo University [56]. The aim of the program was to collect monitoring data on POPs adhered to plastic pellets. The program (which can be characterized as a voluntary citizen science program) has participants in more than 50 countries [56]. Yeo et al. [57] describe how the implementation of the IPW program in Australia and New Zealand has been used to collect data. The authors found that the science communication part of the IPW program was so effective that it could be used to generate awareness of both plastic debris and POPs. These two types of pollution are interconnected to some extent, since POPs tend to adsorb strongly to plastic debris, making plastic debris a potential vector for environmental transport of POPs [58] (also discussed by [59, 60]). Since plastic pollution is often visible (especially for meso- and macroplastic), the environmental risk is more readily perceived than risk from hazardous chemicals such as POPs. The visibility generates a higher awareness of the problem than for less visible problems, leading to significant involvement in CS projects, and possibly policy measures as those described above for Rwanda. Furthermore it can also be used to increase the awareness and improve the risk perception or other less visible, but equally problematic, environmental problems, such as the contamination of POPs [57].

Due to the expanding data available from beach cleanup programs, scientists are now using these data to evaluate the ecological importance of plastic debris. Wilcox et al. [61] used expert elicitation to score impact from different types of plastic marine debris. In order to do so, those authors conducted the threat assessment by focusing on the most common types of litter found along the world's coastlines, based on data gathered during three decades of international coastal cleanup efforts [61]. The authors argued that the approach opened opportunities both for policybased and consumer-driven changes in plastics, by focusing effort on the plastic debris with the highest demonstrable impact on ecologically important taxa serving as indicators of marine ecosystem health [61]. 


\section{Expanding Citizen Science: The Bottom-Up Approach}

Thus, citizen science can serve to integrate citizens in scientific projects increasing the scientific data pool and enabling citizens to obtain a more informed foundation for developing risk perception. There are however limitations to the current use of CS. Projects such as Marine LitterWatch and International Pellet Watch can be characterized as top-down CS, where scientists define the problem and ask citizens to help collect data to either illuminate and/or possibly solve the problem. While this is important work, it is dependent on and limited to the problems scientists have identified, and the citizens are primarily seen as "supporters." In this context, we refer to this as a top-down CS approach. An alternative (but not mutually exclusive) approach can be characterized as a bottom-up approach, where citizens are included already in the problem definition phase, potentially transcending a role as "supporters." This can facilitate stronger cooperation between scientist and citizens and lead to a more sustainable development [62]. Such an approach has some advantages that we will address below, before concluding the chapter by evaluating to what extent CS can serve as a valuable tool for increasing and qualifying risk perceptions.

Clausen [62] argues that the current dominating paradigm for inclusion of specific stakeholders in policy and environmental planning processes (i.e., governance) comes at the cost of the participation and influence of citizens in a broader sense and has a tendency to alienate citizens from nature and nature conservation. This is due to the focus on expert elicitation in the governance process (although the current governance paradigm includes more and different stakeholders compared to traditional expert-centered planning and decision processes), which has a tendency to decouple political processes from lay persons' perception of the problem. Clausen [62] further argues that by involving citizens in evolving shared norms and activities within a given topic, it is possible to facilitate the development of a community governance and thereby initiate a continuous sustainable process where citizens gain stronger ownership of (managing) the environment they are a part of. The earlier inclusion of (local) citizens can further strengthen the scientific foundation for addressing an environmental problem. Valinia et al. [63] discussed how the inclusion of local citizens' knowledge about a Swedish lake could improve the scientific foundation for assessing the anthropogenic impact on the water quality. The authors argued that local citizens possessed historical knowledge, which they used to conceptualize reference conditions in regard to the environmental state of the lake [63]. They showed that by comparing local knowledge with data from fish and water chemistry monitoring, as well as paleolimnological reconstructions of water quality, local citizens' knowledge corresponded well with the historical data, helping to deliver a more detailed picture of the present state of the lake. This local knowledge enabled a better assessment of the water quality and could thus contribute to developing a better scientific foundation for regulation [63]. And this is not all. As shown by Nielsen et al. [64], this kind of involvement of local citizens in natural resource management certainly broadened out the total 
scope of environmental management, integrating biological, cultural, and social dimensions, and through this leads to a growing responsibility within the local community regarding nature protection.

If citizens are included in the problem formulation phase of a risk assessment and meet the scientists in a mutual, not just formal, dialogue, their understanding of the risk will often be more qualified. This again can lead to citizens contributing to determining how risks are best addressed in their local community, which would leave them with higher degree of control over the risk, and if citizens are included in giving different risks priority, this might also ensure that they engage in making the local community a responsible actor in the nature protection. Different kinds of bottom-up CS confirm this, as, for instance, described by [65], discussing experiences from a project in a deprived urban community in London. Since some of the drivers for risk perceptions relate to how known the risk is (driver 3), whether it is faced voluntary (driver 1), and the degree of control over the risk (driver 2), a better integration of citizens via the bottom-up approach might ensure that citizens obtain a more qualified risk perception.

\section{Concluding Remarks}

The risk perception of plastic pollution has developed markedly since the first discoveries of oceanic plastic debris. In the first part of this chapter, we have illustrated how this development can largely be described with eight common drivers for risk perception. Common themes for many of these drivers are to what degree the problems of character, magnitude, potential impact, and solutions are understood. This implies that greater insight into these aspects by citizens will almost inevitably result in a more informed risk perception. Risk drivers such as how known the risk is (driver 2), possible benefits associated with the risk (driver 3 ), the novelty of the risk (driver 7), and whether the risk is tangible or abstract (driver 8) are all influenced by the degree of insight people have. In the case of plastic pollution, this greater insight has been built up over the last few decades and has stimulated a development toward a much broader understanding of the problem and a higher degree of perceived risk associated with plastic pollution.

In the second part of the chapter, we address how citizen science generates more awareness of the plastic pollution problem, improves risk perception, evolves science, and even contributes to actively addressing the plastic pollution problem. Classical top-down form of citizen science has had a significant impact of risk perception and subsequent societal measures. However, this type of mode 2 research, where scientists and citizens collaborate more systematically, has the potential to improve this positive process even further. We describe how bottom-up citizen science has been used to improve public participation, increase local ownership, improve scientific understanding, and enhance transparency within several different environmental topics. Within the area of plastic pollution, bottom-up CS has the potential to enable citizens to address the local pollution 
they are most concerned with, and by involving local citizens, they get higher sense of control over the risk (driver 2). The citizens also generate a better understanding of the consequences of the plastic pollution for the environment (driver 4). Any local conflicts where pollution with plastic is in favor of some citizens or organizations (e.g., cosmetics producers) and not others can further be illuminated in such a process (driver 6), enabling a dialogue about positive and negative consequences of the different behaviors. Finally, the bottom-up citizen science approach has the potential to make the problem even more explicit to the citizens and thereby enhancing the risk perception by reducing the "Giddens paradox" (driver 8). The risk perception of plastic pollution has thus developed markedly over the last decades, due to increased scientific understanding and greater involvement of citizens in collection scientific data.

Acknowledgement This work is supported by the Villum Foundation. VILLUM FONDEN

\section{References}

1. Sjøberg L, Moen BE, Rundmo T (2004) Explaining risk perception. An evaluation of the psychometric paradigm in risk perception research. Rotunde publikasjoner, Rotunde no. 84

2. Syberg K, Hansen SF (2016) Environmental risk assessment of chemicals and nanomaterials — the best foundation for regulatory decision-making? Sci Total Environ 541:784-794

3. Beck U (1986) Risk society: towards a new modernity. Sage, London

4. Silvertown J (2009) A new dawn for citizen science. Trends Ecol Evol 24:467-471

5. Kramm J, Völker C (2017) Understanding the risks of microplastics. A social-ecological risk perspective. In: Wagner M, Lambert S (eds) Freshwater microplastics: emerging environmental contaminants? Springer, Heidelberg. doi:10.1007/978-3-319-61615-5_11 (in this volume)

6. Slovic P, Fischhoff B, Lichtenstein S (1981) Facts and fears: societal perception of risk. NA-Adv Consum Res 8:497-502

7. Starr C (1969) Social benefit versus technological risk. Science 165:1232-1238

8. Giddens A (2011) The politics of climate change. Polity Press, Cambridge

9. EC (2009) Europeans' attitudes toward chemicals in consumer products: risk perception of potential health hazards. European Commission, Directorate-General for Communication ("Research and Political Analysis" Unit), Bruxelles, Belgium

10. Torgersen $\mathrm{H}$ (2004) The real and perceived risks of genetically modified organisms. EMBO Rep 5:17-21

11. Schmidt CW (2008) The yuck factor when disgust meets discovery. Environ Health Persp 116: A524-A527

12. Kenyon KW, Kridler E (1969) Laysan albatross swallow indigestible matter. Auk 86:339-343

13. Chenxi W, Kai Z, Xiong X (2017) Microplastic pollution in inland waters focusing on Asia. In: Wagner M, Lambert S (eds) Freshwater microplastics: emerging environmental contaminants? Springer, Heidelberg. doi:10.1007/978-3-319-61615-5_5 (in this volume)

14. Khan FR, Mayoma BS, Biginagwa FJ, Syberg K (2017) Microplastics in inland African waters: presence, sources and fate. In: Wagner M, Lambert S (eds) Freshwater microplastics: emerging environmental contaminants? Springer, Heidelberg. doi:10.1007/978-3-319-616155_6 (in this volume)

15. Dris R, Gasperi J, Tassin B (2017) Sources and fate of microplastics in urban areas: a focus on Paris megacity. In: Wagner M, Lambert S (eds) Freshwater microplastics: emerging 
environmental contaminants? Springer, Heidelberg. doi:10.1007/978-3-319-61615-5_4 (in this volume)

16. Carpenter EJ, Smith KL Jr (1972) Plastic on the Sargasso Sea surface. Science 175:1240-1241

17. Ryan P (2015) A brief history of marine litter research. In: Bergmann M, Gutow L, Klages M (eds) Marine anthropogenic litter. Springer International Publishing, Berlin

18. Van Franeker JA (1985) Plastic ingestion in the North Atlantic fulmar. Mar Pollut Bull 16:367-369

19. Ryan $P$ (1987) The incidence and characteristics of plastic particles ingested by seabirds. Mar Environ Res 23:175-206

20. Harper PC, Fowler JA (1987) Plastic pellets in New Zealand storm-killed prions (Pachyptila spp.), 1958-1977. Notornis 34:65-70

21. IMO (2016) Annex V: prevention of pollution by Garbage from Ships. International Maritime Organisation, United Nations. Available at: http://www.imo.org/en/OurWork/environment/ pollutionprevention/garbage/Pages/Default.aspx

22. Brennholt N, Heß M, Reifferscheid G (2017) Freshwater microplastics: challenges for regulation and management. In: Wagner M, Lambert S (eds) Freshwater microplastics: emerging environmental contaminants? Springer, Heidelberg. doi:10.1007/978-3-319-61615-5_12 (in this volume)

23. Moore CJ, Moore SL, Leecaster MK, Weisberg SB (2001) A comparison of plastic and plankton in the North Pacific central gyre. Mar Pollut Bull 42:1297-1300

24. Watts A (2015) Are we really "choking the ocean with plastic"? Tracing the creation of an eco-myth. Available at: https://wattsupwiththat.com/2015/12/24/are-we-really-choking-theocean-with-plastic-tracing-the-creation-of-an-eco-myth/

25. GESAMP (2015) Sources, fate and effects of microplastics in the marine environment: a global assessment. International Maritime Organisation (IMO), London

26. Thompson RC, Olsen Y, Mitchell RP, Davis A, Rowland SJ, John AWG, McGonigle D, Russell AE (2004) Science 304:838

27. Reuters (2015) Plastic pollution devastating the world's oceans. Reuters International, May 13, 2015. Available at: http://www.reuters.com/video/2015/05/13/plastic-pollution-devastat ing-the-worlds?videoId $=364209898 \&$ videoChannel $=6 \&$ channelName $=$ Technology

28. REMA (2012) Rwanda against plastic bags. Rwanda Environment Management Authority (REMA) Available at: http://www.rema.gov.rw/index.php?id=10\&tx_ttnews\%5Btt_news\% $5 \mathrm{D}=36 \& \mathrm{cHash}=6$ fee2e51447d80ce6ce1d7d778969aea

29. Khan FR, Mayoma B, Biginagwa FJ, Syberg K Microplastics in inland African waters: presence, sources and fate. In: Warger M, Lambert S (eds) Freshwater microplastics emerging environmental contaminants? Springer Nature. doi:10.1007/978-3-319-61615-5_6 (in this volume)

30. EC (2015) Directive (EU) 2015/720 of the European Parliament and of the council of 29 April 2015 amending directive 94/62/EC as regards reducing the consumption of lightweight plastic carrier bags. European Commission, Bruxelles

31. Eriksen M, Thiel M, Prindiville M (2017) Microplastic: what are the solutions? In: Wagner M, Lambert S (eds) Freshwater microplastics: emerging environmental contaminants? Springer, Heidelberg. doi:10.1007/978-3-319-61615-5_13 (in this volume)

32. EC (2015) Communication from the Commission to the European Parliament, the council, the European Economic and Social Committee and the Committee of the Regions, closing the loop - an EU action plan for the circular economy, European Commission COM(2015) 614 final, Brussels, Belgium

33. North Sea Foundation and Plastic Soup Foundation (2012) Beat the microbead. International campaign against microbeads in cosmetics. Available at: https://www.beatthemicrobead.org/en/

34. Greenpeace (2016) Petition to phase out microbeads. Available at: https://secure.greenpeace. org.uk/page/s/ban-microbeads 
35. State of California (2015) Assembly bill no. 888 waste management: plastic microbeads. CA. Available at: https://leginfo.legislature.ca.gov/faces/billTextClient.xhtml?bill_ $\mathrm{id}=201520160 \mathrm{AB} 888$

36. Energy and Commerce Committee (2016) Bipartisan legislation to phase out of plastic microbeads from personal care products. Available at: https://energycommerce.house.gov/ news-center/press-releases/breaking-bipartisan-bill-banthebead-now-law\#sthash.YJJa0C9E. dpuf

37. Chemical Watch (2016) Canada consults on proposed microbeads regulations. Available at: https://chemicalwatch.com/44980/

38. Eriksen M, Mason S, Wilson S, Box C, Zellers A, Edwards W, Farley H, Amato S (2013) Microplastic pollution in the surface waters of the Laurentian Great Lakes. Mar Pollut Bull $77: 177-182$

39. Jambeck J, Geyer R, Wilcox C, Siegler TR, Perryman M, Andrady A, Narayan R, Law KL (2015) Plastic waste inputs from land into the ocean. Science 347:768-771

40. Dickinson JL, Zuckerberg B, Bonter DN (2010) Citizen science as an ecological research tool: challenges and benefits. Annu Rev Ecol Evol Syst 41:149-172

41. BirdLife Australia (2016) Atlas \& Birdata. Available at: http://birdlife.org.au/projects/atlasand-birdata

42. BSBI (2016) Herbaria@home, recording historical biodiversity. Botanical Society of Britain \& Ireland, Shirehampton. Available at: http://herbariaunited.org/atHome/

43. The Air Quality Egg Project (2016) Available at: http://airqualityegg.com/

44. UoI (2010) IDAH2O master water steward program. University of Idaho, Idaho. Available at: http://www.uidaho.edu/extension/idah2o/about

45. Cohn JP (2008) Citizen science: can volunteers do real research? Bioscience 58:192-197

46. Beecher N, Harrison E, Goldstein N, McDaniel M, Field P, Susskind L (2005) Risk perception, risk communication, and stakeholder involvement for biosolids management and research environ. J Environ Qual 34:122-128

47. Ruiz-Mallén I, Riboli-Sasco L, Ribrault C, Heras M, Laguna D, Perié L (2016) Citizen science: toward transformative learning. Sci Commun 38:523-534

48. Gibbons M, Limoges C, Nowotny H, Schwartsman S, Scott P, Trow M (1993) The new production of knowledge - the dynamics of science and research in contemporary societies. Sage, London

49. Hidalgo-Ruz V, Thiel M (2015) The contribution of citizen scientists to the monitoring of marine litter. In: Bergmann M, Gutow L, Klages M (eds) Marine anthropogenic litter. Springer International Publishing

50. NOAA (2015) How beach cleanups help keep microplastics out of the Garbage Patches. Available at: http://response.restoration.noaa.gov/about/media/how-beach-cleanups-helpkeep-microplastics-out-garbage-patches.html

51. NOAA (2016) Marine debris tracker. Available at: https://marinedebris.noaa.gov/partnerships/ marine-debris-tracker

52. EEA (2015) Marine litter watch. European Environmental Agency, Copenhagen. Available at: http://www.eea.europa.eu/themes/coast_sea/marine-litterwatch

53. Kallan G, Plasdorf-Vildrik LJ, Christiansen MM, Wagner SB, Søgaard S, Edelfsen SA (2016) Plast Ik. Et studie af plastforurening i Roskilde Fjord. Bachelor project, Roskilde Univerity, Denmark. (in Danish)

54. Hidalgo-Ruz V, Thiel M (2013) Distribution and abundance of small plastic debris on beaches in the SE Pacific (Chile): a study supported by a citizen science project. Mar Env Res 87-88:12-18

55. Lavers JL, Oppel S, Bond AL (2016) Factors influencing the detection of beach plastic debris. Mar Environ Res 119:245-251

56. IPW (2015) International Pellet Watch. Available at: http://www.pelletwatch.org/

57. Yeo BG, Takada H, Taylor H, Ito M, Hosoda J, Allinson M, Connell S, Greaves L, McGrath J (2015) POPs monitoring in Australia and New Zealand using plastic resin pellets, and 
international Pellet watch as a tool for education and raising public awareness on plastic debris and POPs. Mar Pollut Bull 101:137-145

58. Syberg K, Khan FR, Selck H, Palmqvist A, Banta GT, Daley J, Sano L, Duhaime MB (2015) Microplastics: addressing ecological risk through lessons learned. Environ Toxicol Chem 34:945-953

59. Scherer C (2017) Interactions of microplastics with freshwater biota. In: Wagner M, Lambert S (eds) Freshwater microplastics: emerging environmental contaminants? Springer Nature, Heidelberg. doi:10.1007/978-3-319-61615-5_8 (in this volume)

60. Lambert S, Wagner M (2017) Microplastics are contaminants of emerging concern in freshwater environments: an overview. In: Wagner M, Lambert S (eds) Freshwater microplastics: emerging environmental contaminants? Springer, Heidelberg. doi:10.1007/978-3-319-616155 _1 (in this volume)

61. Wilcox C, Mallos N, Leonard GH, Rodriguez A, Hardesty BD (2016) Using expert elicitation to estimate the impacts of plastic pollution on marine wildlife. Mar Policy 65:107-114

62. Clausen LT (2016) Re-inventing the commons: how action research can support the renewal of sustainable communities. Commons, sustainability, democratization: action research and the basic renewal of society. In: Hansen HP, Nielsen BS, Sriskandarajah N, Gunnarsson A (eds) . Taylor \& Francis, New York, pp 29-52. (Routledge Advances in Research Methods; No. 19)

63. Valinia S, Hansen HP, Futter MN, Bishop K, Sriskandarajah N, Fölster J (2012) Problems with the reconciliation of good ecological status and public participation in the water framework directive. Sci Total Environ 433:482-490

64. Nielsen H, Hansen HP, Sriskandarajah N (2016) Recovering multiple rationalities for public deliberation within the EU water framework directive. In: Hansen HP, Nielsen BS, Sriskandarajah N, Gunnarsson A (eds) Commons, sustainability, democratization: action research and the basic renewal of society. Taylor \& Francis, New York, pp 190-214. (Routledge Advances in Research Methods; No. 19)

65. Egmose J (2016) Organising research institutions through action research. In: Gunnarsson E, Hansen HP, Nielsen BS, Sriskandarajah N (eds) Action research for democracy. Taylor \& Francis, New York, pp 182-198. (Routledge Advances in Research Methods; No. 17)

Open Access This chapter is licensed under the terms of the Creative Commons Attribution 4.0 International License (http://creativecommons.org/licenses/by/4.0/), which permits use, sharing, adaptation, distribution and reproduction in any medium or format, as long as you give appropriate credit to the original author(s) and the source, provide a link to the Creative Commons license and indicate if changes were made.

The images or other third party material in this chapter are included in the chapter's Creative Commons license, unless indicated otherwise in a credit line to the material. If material is not included in the chapter's Creative Commons license and your intended use is not permitted by statutory regulation or exceeds the permitted use, you will need to obtain permission directly from the copyright holder.

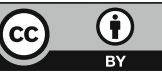

